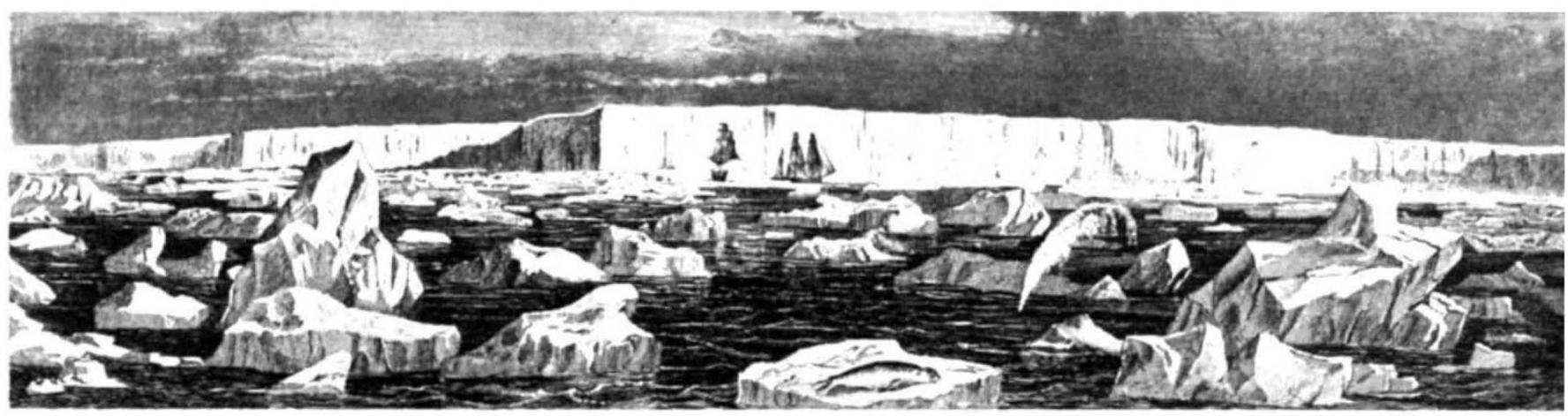

Picture: Mary Evans

\section{Frozen mineral waters}

\author{
Allan Piper looks at the obstacles to exploitation of \\ the vast and varied resources of Antarctica
}

\begin{abstract}
A SSESSMENTS of the economic potenA tial of Antarctica involve issues stretching far beyond the obvious questions of how much and what sort of wealth might be there for the taking. With conditions on the continent hostile and often unpredictable, the successful operation of man, machines and extraction plant is hampered by extremes of climatic behaviour. Huge costs are imposed by Antarctica's extreme distances from the major centres of the commercial world. From the tip of the Antarctic Peninsula the journey to Cape Town is over 4,000 miles, and distances to the principal ports of the Northern Hemisphere exceed 7,000 miles. Moreover, during the winter months much of the continent is inaccessible by sea.
\end{abstract}

But there are other problems too, problems of particular relevance to any future sessions of the Law of the Sea Conference. The legal position in Antarctica is far from certain because nobody has been able to decide to whom the continent should belong. Territorial sovereignty is, and always has been, very much an open question, and the political jealousies run very deep. It is easy to see why. The history of Antarctica is characterised by diplomatic confusion. Conflicting claims for its discovery have never been satisfactorily settled, and in any case none of them was supported with the conventional backing of permanent occupation until over 120 years after the continent first became known around 1820 .

What is certain is that a drive to satisfy commercial demands lay behind the eventual discovery of Antarctica, probably by the sealers who by the 1820 s had penetrated southern waters as far as the South Shetland Islands bordering the Antarctic Peninsula; over the following century the whaling industry grew to become Antarctica's principal resource in the wake of brutal over-exploitation of the native fur seals and elephant seals. By 1959, when the Antarctic Treaty was signed, annual whale catches had risen to over 40,000 .

Throughout the expansion of the whaling industry, however, commercial interest in Antarctica moved steadily back into second place as the continent became increasingly prized for its prestige value and potential strategic advantages. By the close of World War II national rivalries were running high. Seven countries-Argentina, Australia, Britain, Chile, France, Japan, and Norway-had asserted territorial claims and backed them up with permanent bases.

With $80 \%$ of Antarctica neatly divided into pie-slices the geographical borders became more satisfactorily defined than the diplomatic boundaries. Along with the seven existing claimants both the USA and the Soviet Union had established presences on the continent, but neither recognised other territorial claims and neither asserted any. Tensions between Argentina, Britain and Chile, whose claims partially overlap, had stretched to breaking point.

Taken in this context, the signing of the Antarctic Treaty in 1959 must be seen as a major diplomatic achievement. Belgium, New Zealand and South Africa joined the other nine states in agreeing to maintain Antarctica free of military presence, and to hold all territorial claims in abeyance, so that just as no new claim can be asserted, so none is recognised and none challenged.

It would be too charitable to suggest that none of the signatories had half an eye to the commercial potential of Antarctica when the treaty was signed, but nonetheless mineral exploration and exploitation rights are not mentionedthe feeling seemed to be that such a recognisably thorny issue could await the still-distant technological develop- ments that would bring Antarctic exploitation closer to the realms of probability. Even seven years later most realistic prognoses tended towards the pessimistic: ". . . the exploitation of significant deposits", said a leading Australian expert, "presents enormous difficulties. It is very doubtful if minerals could be mined economically in the Antarctic, at least in the foreseeable future."

Plausible though they may have been at the time, such assessments reckoned without the economic downturn of the early 1970s, and when the signatories met in Oslo last June for the Eighth Consultative Meeting under the treaty, Antarctic resources and the likely effects of mineral exploration held centre-stage. The talks were predictably inconclusive, with a standstill agreed pending a full investigation of the environmental hazards; but the expression of environmental concern, though laudable, offers only the thinnest of disguises for the political rationale behind the delay. Exploration surveys, under the guise of scientific research, are well within the bounds of the treaty, but nelationships stand to be irreparably undermined if exploitable resources are uncovered and raise again the intractable issue of sovereignty.

\section{Antarctica's resources}

The main resources are fossil fuels. Pre-continental drift reconstructions of the former Gondwana continent indicate that most of the Antarctic continental shelf includes thick sedimentary sequences likely to contain fuel reserves. The research vessel Glomar Challenger has already found evidence of natural gas beneath the Ross Sea, and an American estimate has put reserves in the eastern shelf at around $115 \mathrm{mil}$ lion million cubic feet of natural gas and 45 thousand million barrels of oil -almost ten times the estimated combined oil reserves of the Brent, Ninian and Forties fields of the North Sea. The chances of uncovering significant deposits have become so good that at the close of the Oslo talks one American delegate was moved to ponder openly the political effect of a rich 
strike beneath the zone disputed by Argentina, Britain and Chile.

Evidently the Soviet Union finds the notion equally as intriguing, for less than three weeks later it announced plans to open a new survey base on the Filchner Ice Shelf at the southern end of the Weddell Sea, an area within the disputed territory. Though in itself not a contravention of the treaty, the development is significant because the Soviet Union has never previously shown any interest whatsoever in that part of Antarctica. The Soviet targets are clearly fossil fuels and metallic ores, and it does not require an unduly cynical appraisal to conclude that the main objective of the move is to force an early definition of mineral exploitation rights. "The eastern part of the region", the official statement said, "has many common features with South Africa, the south is reminiscent of the ore-bearing zones of Siberia, while the west is a continuation of the American mountains, famous for their deposits of non-ferrous minerals."

The statement in no way overstates the possibilities, and even though prospecting techniques will be hampered by the enormous overlay of ice, the chances of small Soviet successes must be rated as reasonable. The sedimentary accumulation beneath the Weddel Sea. like those beneath the Ross and Bellingshausen seas, includes up to 15,000 feet of potentially productive strata. The once-contiguous continental shelves off South Africa and South America are already known to contain small fossil fuel reserves.

Opportunities for the discovery of coal reserves and mineral deposits are equally as good on the main landmass. The extensive coal deposits which crop out throughout eastern Antarctica, particularly in the Horlick, Prince Charles and Pensacola Mountains, and in Victoria Land and the George V Coast, suggest that reserves within Permian sandstones may extend at depth beneath the entire continent. As for metallic and non-metallic minerals, over 200 species have been recorded from localities throughout the continent over the past 75 years. Chromium, cobalt, copper, diamond, manganese, mercury, molybdenum, platinum and uranium are all present, and trace quantities of silver and gold, in amounts of up to 2 and 10 parts per million respectively, have been found in pyrite-rich rocks on the Antarctic Peninsula.

But even after the recent adjustments of world commodity prices, has the exploitation of Antarctic resources become an economic possibility? The answer for the moment must be no. Extracting fossil fuels is hazardous enough in the North Sea, where tens of lives are lost to the industry annually, and where unpredictable climatic behaviour has already pushed production costs way above the earliest estimates. Conditions in Antarctic waters are considerably worse. The depth of water overlying the Antarctic shelves is more than double the average 700 feet in the North Sea, and the insurmountable obstructions of floating pack ice and icebergs scouring the sea floor mean that even such technological innovations as flexible drilling apparatus are unlikely to prove feasible.

Just as daunting and commercially restrictive are the handicaps on the continent itself. Most deposits are isolated, away from the coast, and cut off by glaciers. Coal beds are in the majority of cases limited in their horizontal extent, and mineral finds are usually reported from glacial morraines, so that original outcrops are unknown. Moreover, quality and tenor are generally poor. As for the other minerals, not even high-value metals such as silver, uranium and gold will become viable failing unlikely upward shifts in world prices. The costs of USA gold production would need approximately to double before Antarctic deposits became economic.

\section{Exceptions}

But any thorough assessment of the opportunities must take into account two possible exceptions to this general perspective. The first involves the manganese nodules lining the ocean floor between the continental shelf and the outer boundary of Antarctic territory at the relatively temperate latitude of $60^{\circ} \mathrm{S}$. Manganese nodules are present throughout the world, and with the development of suitable extraction technology are likely to prove an extremely rich resource.

Just as promising is the economic potential of the igneous Dufek Massif in the northern Pensacola Mountains. So far, only viable deposits of ironbearing magnetite ores have been found, but the complex so closely resembles the richly productive Bushveld intrusion of southern Africa that the prospects have to be viewed in a sanguine light. Further, there is no reason why the Dufek Massif need be unique in Antarctica.

In the final analysis, however, it is the biological resources of Antarctica which currently offer the greatest prospects for this future. Seals are now adequately protected under the Antarctic Treaty, and the whaling industry, which has declined from its level of 15 years ago, will probably continue to do so under the likely build-up of adverse world pressure. Even so, Antarctic waters are stocked with a superabundance of krill, Euphausia superba, the small shrimp-like creature forming the staple diet of the whales that visit the region to gorge themselves each year. One estimate has suggested that factory ships could economically take an annual minimum of 270 million tonsan amount far in excess of present yearly world fish catches-without upsetting natural balances.

As for the question of mineral exploitation, this will be discussed when the signatories to the Antarctic Treaty gather in London this summer for a preparatory session ahead of their Ninth Consultative Meeting in Paris next year.

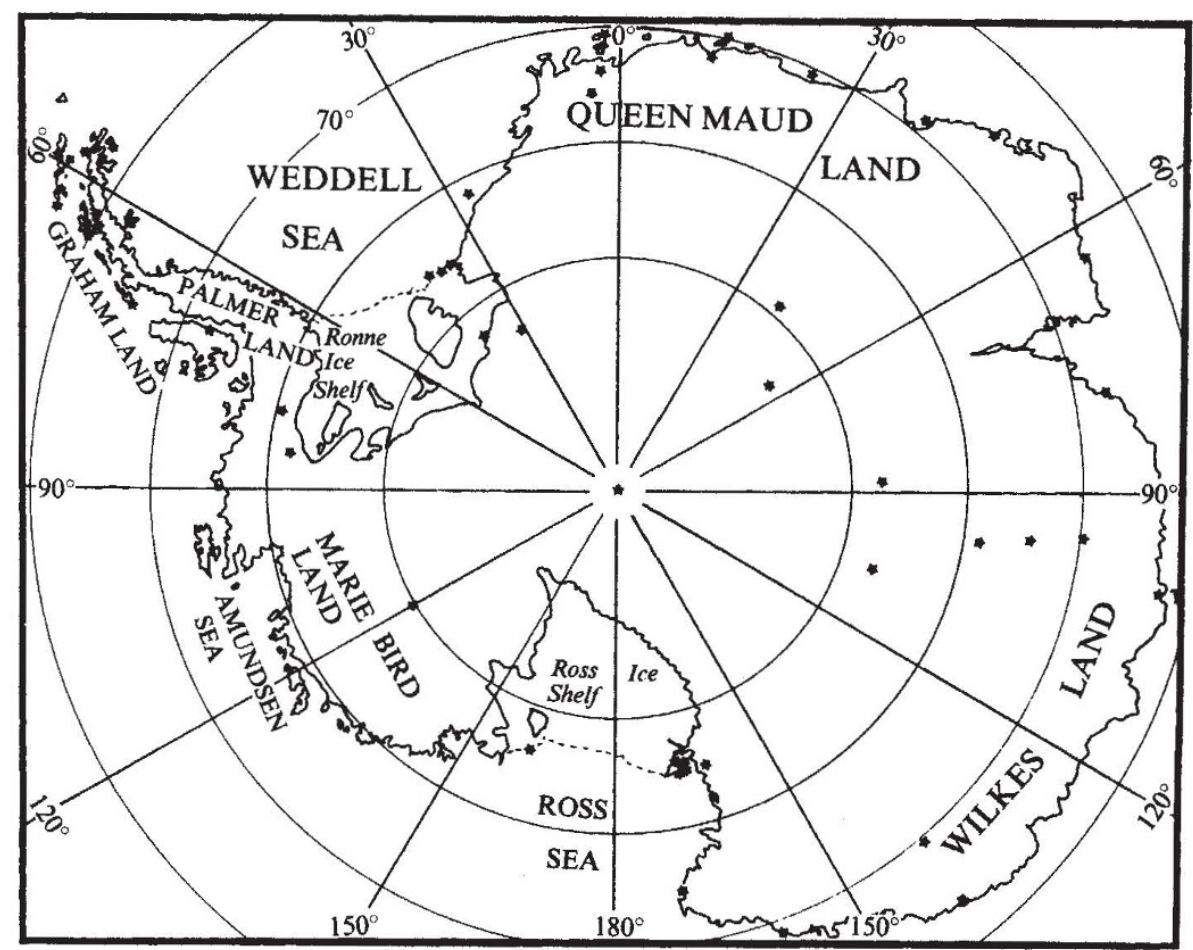

Antarctica, showing scientific stations in operation 1954-1975 